\title{
mal-estar na contemporaneidade: performance e tempo
}

Olgária Matos

A modernidade produzida pelo capitalismo contemporâneo é dominada pelo princípio do desempenho, do rendimento e das performances do trabalhador em seu trabalho. É possível encontrar seu precursor em Antístenes, um dos freqüentadores dos círculos socráticos junto a Platão. Nele encontra-se a noção moderna de que, na moral, o bem é por natureza de difícil acesso e que o esforço é a vitória sobre si, como critério do bem moral. Assim Antístenes anotou: "O sofrimento é um bem”. Mais que isso, em Antístenes encontra-se a primeira descrição da figura do trabalhador que ele mesmo encarna, pois acrescenta à valorização moral do sofrimento a exaltação do trabalho desafiador de limites. De onde, sua referência a Hércules, exemplar figura do "operário fabuloso" e seus trabalhos sobre-humanos". Com efeito, uma de suas obras se intitula Hércules maior ou Sobre a Força. Lembre-se aqui que a personagem de Hércules teve em seu tempo, como no presente, um caráter indispensável. Assim como Carlyle, um dos profetas da religião do trabalho: 'Tu deves, como Hércules, te preencher 
com ocupações e penar bastante." (p.31 LEPENIES). Moralista satisfeito, Antístenes não tem nenhum senso dos cultos religiosos, o que, aliás, menospreza com argumentos "iluministas" do tipo "racionalista". É também inteiramente fechado às Musas a poesia só o interessa se através dela se expuserem ensinamentos morais -, a capacidade de responder a Eros lhe é totalmente estranha. Como Clemente de Alexandria, ele poderia dizer: "O amor é um vício da natureza", "Afrodite, eu a cravaria de flechas, se eu a pegasse". Quanto à imortalidade, esta não passa de uma palavra vazia. Para esse realista sem ilusões, a única coisa que conta no mundo é uma "vida honesta e correta", vivendo "na piedade reverencial e na justiça". Esses traços reunidos constroem a figura do trabalhador. Seu ideal contemporâneo é aquele apto a realizar "metas" e, para isso, deve estar 24 horas por dia, e em período integral, trabalhando, o que é viabilizado pelas novas tecnologias, dos celulares à internet transportável. No capitalismo contemporâneo "domina o cada um por si [...]. A obsessão de eliminar o concorrente na busca do lucro se duplica na vontade também ela aguerrida de eliminá-lo na conquista de postos. A cultura do ódio promove a eliminação em lugar da cooperação. As solidariedades de classe se desmancham em proveito da ferocidade supostamente favorecedora dos melhores." Trata-se de um ambiente de trabalho policiado por uma administração que dá conselhos, mas conselhos sem experiência e sem ligação nenhuma com a história do próprio trabalhador. Recusa-se, pois, a temporalidade da experiência, do conhecimento, da felicidade. A temporalidade é institucionalmente organizada, constituindo "o atributo mais eminente da dominação", pois corresponde a um encolhimento do "espaço de experiências" na vida social e de liberdade. Liberdade essa tanto de acesso ao passado e ao futuro quanto de construção de uma subjetividade democrática que representa a construção de uma história e de uma identidade comum, na medida em que esta designa um espaço de objetivos de significações partilhadas.

A temporalidade aderida à aceleração do presente - o presenteísmo - apoderase de todos os espaços democráticos, a começar pela educação, que deixa de ser "educação para a liberdade", para direitos e deveres correspondentes, tornando-se "educação para a adaptação", na proliferação de direitos sem a lei pan-inclusiva que deveria presidi-los. Seus efeitos na educação se constituem no desaparecimento da noção de "cultura geral" pela de "cultura comum", cuja finalidade essencial é "preparar os jovens para entrar no mundo tal como ele é" 4 . Essa adesão ao presente plano, caso permita algum sonho - este é paradoxal - sonha tão somente com o status quo, deseja que nada de novo venha a abrir o tempo histórico e o futuro. O tempo na contemporaneidade é fatalizado pela ordem das urgências, que significa uma oscilação na razão instrumental, o culto dos meios e o esquecimento dos fins. Ele é o reino das revoluções tecnológicas do progresso.

A modernidade ocidental nasce sob o signo da mudança incessante. Seu protótipo foi o Iluminismo filosófico e científico e seu desejo de claridade. Com a metáfora da luz, o Iluminismo ${ }^{5}$, no século XVIII europeu, inaugura a crença no progresso científico, político, social, moral e econômico contra as trevas do obscurantismo. O Iluminismo filosófico na política funda a noção de espaço público, aquele que é comum a todos e não propriedade de poucos, e acessível a todos e não privilégio de alguns. Assim, igualdade, liberdade, fraternidade constituíram, até há pouco, o 
ideário mais nobre do humanismo moderno. Foi esse imaginário coletivo que deu conformidade ao homem-cidadão cuja dignidade esteve resguardada pelo direito e pela lei. Mesmo que esses ideais tenham se realizado apenas para uma classe da sociedade - no caso a burguesia ascendente no poder -, tais valores, não obstante, permaneceram como idéias reguladoras, como exigência de vigência para todos. Pois "se nem todos os homens são felizes, todos têm direito a sê-lo" (KANT). A partir da revolução francesa, com o estabelecimento das funções públicas, procurou-se garantir a continuidade das políticas de alcance social, independentemente da alternância dos governantes no poder, de suas vontades particulares e da prática do favor, características do Antigo Regime. Uma sociedade republicana e emancipada da miséria e do medo encontra-se em estado de maioridade, distante de qualquer tutela, pois todos, ricos e pobres, são igualmente protegidos pela lei. Modernidade veio a significar direito a ser atendido prontamente, e com respeito, na saúde; a ler pensadores clássicos no original grego ou latino porque ricos e pobres dividiam os mesmos bancos escolares. Idosos, portadores de deficiências - o que hoje se denomina improdutivos - não mais estavam excluídos do espaço social. Nas condições contemporâneas de reprodução e acréscimo do capital, os direitos sociais que constituíam os elementos críticos do capitalismo vêm a ser obstáculos no capitalismo financeirizado - de onde derivam as sucessivas flexibilizações dos direitos sociais. Lembrese que diferem as temporalidades do mercado e do Estado, uma vez que o mercado opera no curto prazo e os serviços públicos na duração e no tempo longo, como a saúde, a educação, os transportes, a aposentadoria, etc. Assim, a lógica do mercado e da rentabilidade a curto prazo passa a abranger todas as dimensões do tempo. As privatizações correspondem, desse modo, à transferência do público ao privado da garantia de futuro de seus cidadãos: "O Estado cede, pois, sua capacidade de garantir o futuro para o Mercado" [...]. Duas lógicas temporais estão confrontadas: por um lado, a dos Estados, garantidores da lentidão e do durável; de outro, a dos Mercados, ávidos de
"A organização institucional do

tempo é a figura

mais eminente da

alienação e da

dominação do

homem pelo mercado

mundializado,

pois cada um

perde o sentido e $o$

mestrado do tempo

e de sua vida." velocidade e rendimento a curto prazo." ${ }^{\prime 6}$ A tendência à dissolução dos Estados nacionais pelo capital transnacional privatizante - cujos critérios de autoridade correspondem aos interesses dos conglomerados no Poder - e a determinação de todas as esferas da vida pelas leis do mercado dissolvem a separação entre o público e o privado, transformam o espaço público em imagem pública e o cidadão 
em cidadão-consumidor, como se observa no advento do marketing político. Com efeito, as atuais campanhas eleitorais inscrevem-se nas mudanças da esfera pública e no advento de práticas persuasivas ligadas à "peoplelização" segundo o modelo da imprensa tablóide inglesa das "celebridades" e do colunismo social. Dão-se na adoção dos recursos do show business, com os políticos imitando a vida de stars, sob a hegemonia das mídias de massa, da publicidade, do talk show, o conjunto atendendo à lógica comercial e recreativa.

Até há pouco diferenciavam-se propaganda e publicidade. No século XVIII europeu, a propaganda de idéias correspondeu à constituição de um espaço público nascido dos salões literários, a leitura consistindo no meio por excelência nobre da propagação dos valores de aprimoramento da convivência, da confiança, da solidariedade e da philia social. A propaganda moderna fazia parte do ideário iluminista de combate a todos os tipos de preconceito e de obscurantismo, na política, na moral, na ciência, nas artes. O espaço público foi a contrapartida da vida na Corte, esta com seu culto da aparência e da imagem pública do valor de alguém.

Com efeito, ser escolhido pelo Rei-Sol, na França de Luís XIV, era o apogeu da vida pública, a partir do momento em que suas formas alternativas, ligadas à cidade e ao civismo, desapareceram com a derrota dos nobres que se recusavam a abandonar Paris e se confinar na Corte. Vencida a Fronda, a capital se transfere de Paris para Versalhes. A vida pública se reduz à vida em público com sua subseqüente teatralização. A Corte, sabe-se, é o lugar da vaidade e da dissimulação porque é preciso conservar, a todo custo, o crédito, o favor recebido, a fortuna, razão pela qual foi configurado o laboratório dos moralistas, esses analistas das paixões humanas. No século XVIII, o duque de Nivernais escreve um breve tratado para uso dos cortesãos caídos em desgraça, quando perdem honras e fortuna. $\mathrm{Na}$ esfera pública, ao contrário, viria a propagar-se o ideal político democratizante, fundado no debate público, na presença dos protagonistas ou por escrito, o que supunha o fortalecimento do âmbito da argumentação e da informação. Já a publicidade busca tornar visíveis as propriedades reais ou imaginárias de um produto segundo a lógica da compra e da venda para fins de reposição, acúmulo e acréscimo de um capital investido e, no caso, o êxito eleitoral.

A política "people" associa propaganda e publicidade, advindo o marketing político dirigido ao conjunto dos consumidores de mídias, isto é, o corpo de eleitores. "Revolução conservadora", uma vez que se assiste ao retorno do privado, da intimidade pessoal e da personalização do poder. De onde o tratamento cada vez mais agressivo nas campanhas eleitorais. $\mathrm{A}$ mise-en-scène promocional da intimidade tem por corolário a imprensa sensacionalista e vedetizante, que expõe a intimidade e vive de escândalos, como denúncias de várias ordens e a curiosidade com respeito a preferências sexuais ou alimentares das celebridades. Os acontecimentos tomam a fórmula dos faits-divers: não são estranhos à forma pós-moderna da política traços populistas, pautados tanto pelo fetiche das pesquisas de opinião como responsáveis pela fabricação de uma imagem pública destinada a se tornar objeto de ódio ou amor. A personalização da política contradiz a concepção parlamentar das instituições republicanas Por isso, o debate nas eleições se guia pela lógica da conquista a qualquer preço dos cargos eletivos, apelando para um sistema de preconceitos, 
suscitando o exercício sem escrúpulos de ressentimentos, fruto de uma "rivalidade mimética" com aquele que se ataca. O cidadão, convertido em telespectador e "comentarista" político, confirma as carências e insuficiências do jogo político tradicional. Assim, também a sucessão de escândalos só pode ser mantida pelos procedimentos próprios à média, capaz de reunir em um todo "coerente" um conjunto de elementos desordenados de modo a impedir a reflexão, pois não há como distinguir o que é significativo e o que é insignificante nos noticiários. Cria-se um universo povoado de heróis e anti-heróis, de vítimas e de seus salvadores.

O marketing político se desenvolve no campo ideológico da "autenticidade" e da glorificação do homem comum. Alain Ehrenberg indica as conseqüências: a autenticidade que se transforma em "culto da transparência”, isto é, da aparência, os políticos treinados como profissionais da comunicação e das "promoções do dia". Nesse sentido, em "Rua de Mão Única", Walter Benjamin escreveu: "O homem pode, se for o caso, colocar ostensivamente sua vida privada em contradição com as máximas que defende implacavelmente na vida pública e considera, secretamente, sem a menor dor de consciência, sua própria conduta como a prova mais constrangedora da autoridade dos princípios que ele exibe." O recurso à injúria com a finalidade de votos é prática herdada do jacobinismo e amplamente evocada pelas revoluções que nela se inspiraram, tendo por base a suposta superioridade moral de seus enunciadores com respeito a seus opositores: "corruptos" perseguidos por Roberspierre e Saint Just (designação que incluía os nobres, os magistrados, os "açambarcadores"); os "renegados"de Lênin (a social-democracia parlamentar de
Kautski); os "degenerados" de Hitler (judeus, ciganos e povos "inferiores"). A compreensão da política na oposição amigo-inimigo adota a prática empresarial da eliminação do concorrente. A partir da concorrência pode ser que se melhorem as mercadorias, mas certamente se pioram os homens. Uma cidade feliz, ao contrário, é aquela que assegura o máximo de sobrevivência, segurança, justiça, liberdade e amizade para o conjunto dos cidadãos. $\mathrm{O}$ espaço público é o que é comum e acessível a todos.

Além disso, "politizar" todas as dimensões da vida, incluindo a intimidade, é a expressão da despolitização total, pois são mobilizados aspectos protofascistas e autoritários de cada um, como bem o revelam as análises de Hannah Arendt sobre o totalitarismo. O teor dos discursos dos candidatos confirma a supressão do debate de idéias pela política reduzida à "prestação de serviços". Que se pense na agenda midiática despolitizadora: cotas compensatórias que substituem o enfrentamento da exclusão econômica e cultural da maioria, quando deveriam ser apenas transitórias; indenizações para as vítimas do terrorismo de Estado e o silêncio sobre suas causas, com a conseqüente manutenção da prática da tortura no país. Também os problemas do cotidiano não são considerados políticos para a agenda eleitoral, que exigiriam questionar as reordenações do capitalismo contemporâneo baseado no descartável e os seus resultados desagregadores na vida urbana, dos congestionamentos à desconsideração de atitudes elementares de convivência, como se dizer "bom-dia" e "com licença", com o que começa, segundo Adorno, toda civilização.

O mercado, já se disse, não reconhece direitos. Em termos, porque vale a "lei do mais forte". Semelhante ao descrito por 
Marx nas "Formações Econômicas précapitalistas", quando massas inteiras de servos da gleba foram arrancados do seu modo de vida, crenças e tradições e violentamente lançados na selva das cidades, vindo a constituir, na Inglaterra, o proletariado moderno, o Estado mínimo para garantir direitos, mas máximo na arrecadação econômica, com a privatização do que é público e a associação do público ao privado com a flexibilização das leis trabalhistas, trazendo de volta, assim, o desemprego crescente, a miséria material e espiritual, de que o tempo é a melhor expressão. Assim, em certos países, será necessário mais tempo de trabalho que em outros para a aquisição de um mesmo bem. O tempo de trabalho oferece a medida exata da geografia das riquezas e da pobreza: "Será preciso 193 minutos de trabalho - ou 1:30 hora de trabalho - para um habitante de Nairobi e 1:17h em Caracas para comprar um Big Mac, enquanto apenas 9 minutos para um cidadão de Chicago, Houston ou Tóquio, 21 em Paris ou Bruxelas."7

A modernidade capitalista, do industrialismo à microeletrônica, supõe a plena luz. Dessa forma, com a substituição dos lampiões a gás pela iluminação elétrica em fins do século XIX, "a Via-Láctea foi secularizada". ${ }^{8}$ Essas palavras não se referem apenas ao desencantamento psíquico e da cultura, mas também ao significado socioeconômico dessa realização: a atividade sem trégua do modo de produção capitalista tornou-a desmedida, não tolerando o tempo noturno de passividade, repouso e contemplação. A partir das nanotecnologias e da microeletrônica, a economia, em sua forma atual de acumulação, exige a extensão e a intensificação da atividade até os últimos limites físicos e biológicos do indivíduo.
Razão pela qual, com a eletrificação, o dia iluminado passa a ter vinte e quatro horas. A organização institucional do tempo é a figura mais eminente da alienação e da dominação do homem pelo mercado mundializado, pois cada um perde o sentido e o mestrado do tempo e de sua vida. Consciente da heteronomia do tempo de trabalho, o Maio de 1968 francês eternizou nos muros da cidade a inscrição: "Não mude de emprego, mude o emprego de sua vida". Viver é mais que sobreviver. Limitados à sobrevivência desfazem-se as máximas morais. Kant escreveu: "Todas as coisas que podem ser comparadas podem ser trocadas e têm um preço; aquelas que não podem ser comparadas não podem ser trocadas, não têm preço, mas dignidade. O mercado, ao contrário, só reconhece os custos: quanto custa um idoso, uma criança, um doente. Tal redução do humano ao "quanto custa" só pode ocorrer no empobrecimento espiritual das democracias, cujo vazio passa a ser preenchido pela hierarquia competitiva da burocracia empresarial, de maneira que "o dirigente deseja ser reconhecido como um ganhador e cujo maior medo é ser etiquetado perdedor." Não tem nenhuma lealdade com aqueles com quem trabalha. É competitivo como o mercado e, como este, exclui aquele que não gera o lucro a qualquer preço. No século XVI, La Boétie escrevia: "Não pode haver amizade onde há deslealdade, desconfiança, injustiça. Entre os maus, quando se reúnem, é um complô, não é companhia; eles não se entretêm, se entretemem; não são amigos, mas cúmplices.".

A ética protestante foi abandonada em nome do espírito capitalista segundo a fórmula de Benjamin Franklin, para quem "tempo é dinheiro". Se tempo é dinheiro, ele não é busca de sentido e 
subjetividade, mas quantidade e heteronomia impostas pela temporalidade do capitalismo tardio - o que só aprofunda a crise do sentido da atividade: a desagregação do sentido da vida em comum arrisca subsumir o homem nessa alienação particular que Hannah Arendt nomeava "acosmismo", o sentir-se estranho no mundo, o sentimento do não pertencimento, o de ser supérfluo. Deve-se, aqui, diferenciar o capitalismo de produção do capitalismo de consumo. No primeiro, o "homem só se sentia em casa quando fora do trabalho e quando no trabalho, estava fora de si" ". $\mathrm{Na}$ sociedade do consumo, quando o homem está fora do trabalho, tampouco se encontra junto a si - o que resulta em uma lógica do desengajamento em relação a um mundo compartilhado e com respeito também a si mesmo, com a dificuldade de criação de laços duradouros, com a obsolescência de valores como respeito, solidariedade, responsabilidade e fidelidade. $\mathrm{O}$ eu procura eliminar todos os laços e sentimentos, reduzidos, agora, a valor de troca, e o mercado conduz ao consumo permanente, induzindo à pressa, constrangendo à rapidez, acentuando a superficialidade nos vínculos. $\mathrm{Na}$ medida em que os sentimentos exigem a duração para se desenvolverem, a aceleração do tempo produz a "pobreza interior".

No século XIX, o aumento tanto absoluto quanto relativo do tempo de trabalho era ainda experimentado como uma espécie de tortura: "Durante um longo período, as pessoas tentaram uma resistência desesperada contra o trabalho noturno ligado à industrialização. Trabalhar antes do alvorecer ou depois do pôr-dosol era considerado imoral". ${ }^{10}$ À maneira dos mercados financeiros, o homem não deve dormir nunca e, assim, institui-se o stress como modo de vida, seja para aqueles ligados a um trabalho, seja para a massa crescente de trabalhadores precários e desempregados. Predomina aqui uma percepção do tempo na qual não mais se tem tempo - sentimento este paradoxalmente presente também entre os desempregados. ${ }^{11} \mathrm{O}$ capitalismo ultraliberal confisca o "espaço da experiência" e o "horizonte de expectativas", resumindose a um "presente perpétuo". ${ }^{12}$
"Um mundo no qual só conta a lei do valor não é o mundo humano, mas o do Capital. Sociedade sem espaço para a fraternidade e para a amizade é também sem compaixão. Essa é uma 'tristeza mimética', pela qual desejamos o fim do sofrimento desse outro nós-mesmos."
A aceleração do tempo do mercado mundial entra em conflito com a temporalidade política das democracias que, desprovidas da experiência do passado e do futuro, não mais dispõem da possibilidade de construção de uma memória representável, isto é, contestável - o que põe em questão o próprio exercício democrático: a contemporaneidade transforma a capacidade humana de duvidar 
em simples falta de convicção. Mas não engajar-se significa "não se empenhar na criação de valores espirituais"13. A pulsão antigenealógica não reconhece nenhuma dívida simbólica com o passado, acreditase que tudo que se é deve-se a si mesmo por uma espécie de auto-engendramento. Sem laços estáveis, produz-se um déficit simbólico no indivíduo e na sociedade, uma vez que valores dependem de um espaço comum de experiências compartilhadas. $^{14}$

A mensuração abstrata do tempo, o trabalho por metas voltadas para performances determinam o decréscimo das faculdades fantasmáticas dos indivíduos submetidos às leis do mercado, isto é, à insegurança e ao medo: "os quadros [de uma empresa] como os funcionários têm o sentimento de não controlar seu ambiente de trabalho e seu futuro. A ameaça consiste em não mais saber em quais critérios se baseiam sanções e recompensas. O êxito ou o fracasso não sendo mais objetiváveis, a partir de elementos concretos, a incerteza domina o medo de ser censurado e de ser visado.[...]. O contexto suscita uma pressão contínua, um sentimento de jamais fazer o suficiente, uma angústia de não se estar à altura do que a empresa exige." ${ }^{15}$ Além disso, o trabalhador está permanentemente sob o controle das empresas nas quais eles se sentem "a mais", "custando muito caro". Perda da identidade profissional e da autoestima constitui uma situação traumática, uma vez que não apenas se perde um posto de trabalho para talvez encontrar um outro como - e antes de tudo - toda uma vida pode ser desfeita: "Advêm sentimentos de desvalorização de si, ruptura de redes de solidariedade, perda de elementos constitutivos da identidade profissional, culpabilidade, vergonha, introversão, dilaceramento da comunidade de trabalho que sustentava a existência (...). A perda de confiança no futuro (...) que se anuncia incompreensível - produz uma profunda ansiedade a que respondem a angústia e o medo do abandono. Angústias arcaicas (...) que podem ter efeitos devastadores". ${ }^{16}$

Modernização significa, assim, a passagem de um mundo com regras conhecidas a um mundo instável e incerto: "A temporalidade contemporânea, assim constituída, produz não o tédio, mas monotonia". Se o tédio (l'ennui), como magistralmente o tematizou Baudelaire em poesia e prosa, é a temporalidade do passado que se repete continuamente no presente - como a moda -, isso não significava perda do futuro. Ao contrário, o "spleenático" vislumbra os paraísos artificiais. Por isso Baudelaire escreve Spleen e Ideal, o spleen como ideal para se contrapor à lógica da produção de mercadorias que é a da multiplicação e da repetição, em princípio ilimitada, do mesmo objeto. O dândi, por seu hábito de "mudar de rosto" e a cada dia surpreender com vestimentas excêntricas, é um ser dotado de singularidade em meio à multidão anônima. O olhar do dândi é capaz de reconhecer no novo o antigo e no antigo o novo, conferindo ao repetitivo a raridade do objeto único, captando na repetição o surpreendente e o extraordinário, como a maquiagem. O pó-de-arroz é como a mica do mármore, que confere à mulher moderna a aura de uma estátua grega.

Já a monotonia é um tempo estagnado, como se a eternidade do céu se plasmasse na Terra. É uma temporalidade que se exprime na ansiedade de "matar o tempo". Tempo patológico, seu vazio de significado tem o stress como ideal porque na monotonia o tempo não passa, pois está alienado na perda do sentido das ações. 
Ele promete a felicidade pelo consumo de bens materiais, mas permanentemente frustra essa esperança, pois não é possível em regime de acúmulo, nem reposição e acréscimo do capital, tampouco democratizar o excedente e o supérfluo. Tempo que se comprime no desejo de consumo ilimitado, por um lado, determina a exaustão, de outro. Diferem a exaustão e o cansaço. Se neste ainda é possível pensar e imaginar, na exaustão não há possibilidade de exercício do pensamento, apenas hiperatividade vazia e também destrutiva. Abulia e sofreguidão constituem dois aspectos do tempo presente, embora aparentemente diversos: "as duas atitudes possuem um traço comum: a reificação de si" ${ }^{17}$, apreensão de si como objeto sem valor e sem sentido. Não podendo escolher nem deliberar acerca do trabalho ou dos usos que poderia fazer do tempo, os homens não são mais agentes mas "agidos": "A atividade tornou-se uma variante da passividade e mesmo onde as pessoas se cansam até seu limite (...), ela tomou a forma de uma atividade - mas para nada - isto é, uma inatividade". ${ }^{18} \mathrm{Ou}$ melhor: vive-se, hoje, uma inflação das possibilidades de significados e, portanto, a impossibilidade em reconhecê-los, seja em nosso mundo interno quanto no externo. Nas palavras de Leder: "O imaginário da sociedade contemporânea encontra-se condicionado (...) por uma extrema saturação. O imaginário caracteriza-se por uma abundância potencial que se apresenta ao alcance da mão mas que se encontra, no entanto, inacessível (...). É precisamente a tensão entre a intuição da presença da satisfação ao alcance da mão e a realidade de seu afastamento e inacessibilidade, o que determina a situação da consciência contemporânea (...). Um exemplo pode ser encontrado na sociedade polonesa, na dicotomia entre sociedade da penúria material e uma sociedade de consumo que ocorreu há quinze anos e transformou totalmente o imaginário social. A mudança da valorização e principalmente da saturação do campo simbólico foi muito mais acelerada que a melhora da qualidade de vida. Paradoxalmente, nos anos sessenta, depois da desestalinização, quando praticamente a totalidade dos poloneses vivia em profunda penúria, mas ao mesmo tempo seu imaginário estava relativamente pouco saturado e, além do mais, estruturado pelo vetor do progresso, a vivência da falta era fraca e cada aquisição material tornava-se um símbolo valorizado positivamente. Nos anos noventa, a transformação econômica melhorou muito a situação material da maioria da população mas, ao mesmo tempo, forçou a integração do campo simbólico dos poloneses no espaço da civilização global. O sentimento de falta e de frustração tornou-se generalizado em todas as camadas da sociedade"19.

Encontra-se aqui o mal-estar contemporâneo que se expressa em um sentimento de monotonia ou "tédio crônico", monotonia que conduz a um desenvestimento em valores. Tudo isso se passa em uma temporalidade monótona, específica de uma sociedade organizada, também, de maneira específica - e que é uma desorganização da consciência social pelo sentimento de desvalorização de si e de humilhação: "A privação específica de si, a questão do sentimento mais do que o da consciência da humilhação, do não reconhecimento de si pelo outro, encontra-se no cerne da humilhação nas sociedades contemporâneas". ${ }^{20} \mathrm{Na}$ vida política contemporânea, "ser é ser percebido", fórmula narcisista, regressiva e onipotente de ocupação do espaço público, a exemplo das cerimônias de destruição de 
que são protagonistas os chamados "amok", que periodicamente atacam escolas, assassinando colegas e professores e depois se suicidam em uma cena preparada e cenarizada para a internet no Youtube, gesto de ressentimento do assassinato em série. A lógica do espetáculo corresponde à do consumo e à substituição permanente de mercadorias, quando nenhuma mercadoria preenche a carência que ela própria suscita. Situação tanto mais humilhante quanto o desejo é movido pela "inveja do tênis", inveja causada pelo sentimento não do justo, mas do injusto, de desigualdade de vantagens e distinções, quanto mais cada um é chamado a consumir e quanto menos poderá fazê-lo.

Desprezo dos dominantes, por um lado, e humilhação dos excluídos do luxo e da abundância, de outro, resultam em apatia e hiperatividade - ambos sintomas de excessos e frustração. Esse tempo patológico é preenchido por esportes radicais, obesidade mórbida, anorexia, bulimia, terrorismos e guerras contemporâneos. Essa agitação permanente é a expressão do empobrecimento psíquico e da perda de qualquer sentido da vida, de onde deriva a "desvalorização de todos os valores". Um mundo no qual só conta a lei do valor não é o mundo humano, mas o do Capital. Sociedade sem espaço para a fraternidade e para a amizade é também sem compaixão. Essa é uma 'tristeza mimética', pela qual desejamos o fim do sofrimento desse outro nósmesmos. Horkheimer anotou quando ainda existia o socialismo do leste: "Os estudantes fugidos do leste, nos primeiros meses depois de sua chegada à Alemanha (FEDERAL), são felizes porque há mais liberdade, mas logo se tornam melancólicos porque não existe amizade alguma." $\mathrm{Na}$ medida em que uma sociedade perde o sentido da fraternidade, acaba por se restringir a um projeto pragmático de adaptação ao status quo do consumo pelo consumo, do crescimento econômico pelo crescimento, do progresso pelo progresso. Sociedade sem amizade e sem compaixão, como escreveu em outro contexto Espinosa no século XVII, "não merece o nome de cidade mas o de solidão" (Espinosa).

(Artigo recebido em novembro de 2008. Versão final em dezembro de 2008). 


\section{Notas}

${ }^{1}$ Pieper, J. Le Loisirfondement de la cultrue. trad. Pierre Blanc, ed Ad Solem,Genebra, 2007, p. 31.

${ }^{2}$ Gaulejac, V. La Société malade de la Gestion. ed Seuil, 2005, p. 210.

${ }^{3}$ Canetti, Elias. Masse et Puissance. trad. R. Rovini. Paris, 1966, p. 422.

${ }^{4}$ Cf. Dufet,F., M. Duru-Bellat. L'bypocrisie scolaire. Pour un collège enfin démocratique?. ed. Seuil, Paris, 2000, p. 178.

${ }^{5}$ Lembre-se que o radical de Aufklärung é klar, Enlightenment, é light, Lumières, Ilustración ou Esclarecimento.

${ }^{6}$ SANTISO, Javier. Leunteur Politique et Vitesse économique, in Malaise dans la temporalité. ed Publications de la Sorbonne, Paris, 2005, org. Paul Zawadiski, p. 124 e 133.

${ }^{7}$ Idem, op. cit. p. 139.

${ }^{8}$ Cf. Benjamin, Walter, arquivo J, Passagen-Werk, ed. Suhrkamp; trad. Le Livre des Passages, ed. Cerf, Paris, 1980.

${ }^{9}$ Cf. Marx, Manuscritos Econômico-filosóficos de 1844. Ed. Martin Claret, SP 2001

${ }^{10}$ Cf. Kunz, Robert, in Avis aux naufragés. ed. Lignes/Manifestes, Paris, 2005, p. 42. Vale lembrar que durante a Idade Média, quando os artesãos deviam, excepcionalmente, trabalhar à noite, era preciso alimentá-los e remunerá-los principescamente. Foi proeza do capitalismo transformar uma modalidade de tortura - a da alienação do tempo - em norma de toda atividade.

${ }^{11}$ Cf Bürge, Noëlle. Minima sociaux et conditions salariales. Ed. Fayard, Paris, 2000.

${ }^{12}$ Que se considere os mais recentes conflitos na França, quando adolescentes, em sua maioria com ascendência árabe e africana, puseram a nu, em um surto incendiário, a perda desse horizonte de expectativas. Excluídos potenciais e também efetivos do mundo do trabalho, não obstante compulsório na organização da vida em função do capital, chamaram a atenção para o sentimento de humilhação decorrente do tratamento que lhes é reservado como cidadãos franceses, mas de "segunda classe".

${ }^{13}$ Cf. Abensour, Miguel. posfácio a Quelques Réflexions sur la philosophie de l'hitlérisme de Emmanuel Levinas. Ed. Rivages, paris, 1997. Algumas reflexões sobre a Filosofia do Hitlerismo", in La Philosophie de l'hitlerisme de Levinas.

${ }^{14}$ É interessante pensar nos ensaios de Walter Benjamin supracitados "O Narrador" e "Experiência e Pobreza", nos quais o filósofo reflete sobre o mundo moderno no qual não é mais possível dar ou ouvir conselhos,onde não pode se desenvolver uma filosofia prática como a contida nas narrativas tradicionais, com suas fábulas, parábolas e provérbios que auxiliavam os homens a enfrentar infortúnio e boa-sorte.

${ }^{15}$ Gaulelad, V., op cit pp. 176-177.

${ }^{16}$ Gaujelac, Vincent de. in La Société malade de la gestion. ed. Seuil, Paris, 2005, p. 164.

${ }^{17}$ Cf. LEDER, Andrzej. La haine comme force formatrice dans le chmps symbolique, xerox, no prelo da publicação do Colóquio de Cérisy, de setembro de 2005.

${ }^{18}$ Anders, Günther. L'Obsolescence de l'Homme. Trad. de Cristophe David. Ed. De L'Encyclopédie. dês Nuisances/Ivrea, Paris, 2002, p.247. O autor refere-se às personagens de Esperando Godot de Beckett. Assim Estragon e Vladimir, que não fazem absolutamente nada, representam, na peça, milhões de homens ativos. 
${ }^{19}$ Malgorzata Szpawoska, Vouloir e Avoir. La Conscience em Pologne du temps du changement, Varsóvia, 2203, apud Leder, A. Introduction à une analyse des transformations de l'intuition du temps dans la culture contemporaine, in Malaise dans la Temporalité, org. Paul Zawadiski, Puyblications de la Sorbonne, Paris, 2002

${ }^{20}$ Haroche, C. Processus psychologique et sociaux de l'humilhation: l'appauvrissement de l'espace intérieur dans l'individualisme contemporain, in L'Humilhation et le Politique, no prelo. Cf. nota 8 , acima. 


\section{Resumo - Resumen - Abstract}

\section{O mal-estar na contemporaneidade: performance e tempo Olgária Matos}

Este ensaio propõe uma reflexão acerca da organização institucional do tempo e do trabalho segundo as exigências do capitalismo contemporâneo e as dinâmicas da modernidade, derivando na alienação e na dominação do homem pelo mercado mundializado. Essa lógica acaba por recusar a temporalidade da experiência, resultando no encolhimento do espaço do conhecimento, da liberdade, da felicidade e legando ao homem a perda do sentido e do mestrado do tempo e de sua vida. Tal ideal é regido pelo princípio do desempenho, rendimento e performances do trabalhador em seu ofício - lógica essa atravessada pela competitividade e uma espécie de cultura do ódio que promove a eliminação e a ferocidade em lugar da cooperação e da solidariedade, apoderando-se ainda de espaços democráticos importantes, como a educação, que deixa de ser "educação para a liberdade" para se tornar "educação para a adaptação".

O tempo na contemporaneidade e o trabalho direcionado a metas, performances são fatalizados pela ordem das urgências, ou seja o culto dos meios e o esquecimento dos fins. Nesse contexto, conceitos como tédio e monotonia devem ser demarcados e diferenciados. Enquanto o tédio configura a temporalidade do passado que se repete continuamente no presente, sem que isso signifique a perda do futuro, a monotonia é um tempo estagnado, uma temporalidade que se exprime na ansiedade de 'matar o tempo'. É um mal moderno, um tempo patológico, pois seu vazio de significado tem o stress como ideal, já que na monotonia o tempo não passa, pois está alienado na perda do sentido das ações. $O$ mal-estar contemporâneo se expressa em um sentimento de monotonia ou "tédio crônico", conduzindo à desvalorização de todos os valores. Na vida política contemporânea, "ser é ser percebido", fórmula narcisista, regressiva e onipotente de ocupação do espaço público, uma lógica do espetáculo que corresponde à do consumo e à substituição permanente de mercadorias, quando nada preenche a carência que elas próprias suscitam. Enfim, o mal-estar contemporâneo disposto nesse tempo patológico está circunscrito a um mundo no qual só conta a lei do valor, não o mundo humano, mas o do capital, sem espaço para fraternidade, amizade e compaixão.

Palavras-chave: tempo, trabalho, capitalismo, modernidade.

\section{El malestar en la contemporaneidad: actuación y tiempo Olgária Matos}

Este ensayo propone una reflexión acerca de la organización institucional del tiempo y del trabajo, de acuerdo con las exigencias del capitalismo contemporáneo y las dinámicas de la modernidad, resultando en la marginación y dominación del hombre por el mercado global. Este razonamiento recusa la temporalidad de la experiencia, lo que resulta en el encogimiento del espacio del conocimiento, de la libertad, de la felicidad, legando al hombre la pérdida del sentido y de la conducción del tiempo y de su vida. Tal ideal se rige por el principio del desempeño, rendimiento y actuación del trabajador en su oficio - razonamiento en que se ven la competitividad y una especie de cultura del odio, que promueve la eliminación y la ferocidad en vez de la cooperación y solidaridad, apoderándose todavía de importantes espacios democráticos como la educación, que deja de ser "educación para la libertad" y pasa a ser "educación para la adaptación".

El tiempo en la contemporaneidad y el trabajo direccionado a metas, actuaciones que se han hecho fatales por el orden de las urgencias, o sea, el culto a los medios y el olvido de los fines. En este contexto, conceptos como tedio y monotonía deben ser delimitados y distinguidos. Mientras el tedio configura la temporalidad del pasado que se repite continuamente en el presente, sin que esto signifique la pérdida del futuro, la monotonía es un tiempo estancado, una temporalidad que se expresa en la ansiedad de "matar el tiempo". Es un mal moderno, un tiempo patológico, pues su vacío de significado tiene el 
estrés por ideal, ya que en la monotonía el tiempo no pasa, pues se encuentra aislado en la pérdida del sentido de las acciones. El malestar contemporáneo se expresa en un sentimiento de monotonía o "tedio crónico", conduciendo a la minusvalía de todos los valores. En la vida contemporánea, "ser es ser distinguido", fórmula narcisista, regresiva y omnipotente de ocupación del espacio público, una lógica del espectáculo que se corresponde con la del consumo y la sustitución permanente de mercancías, cuando nada satisface la carencia que ellas mismas suscitan. En fin, el malestar contemporáneo dispuesto en este tiempo patológico está circunscrito a un mundo en el cual sólo cuenta la ley del valor, y no el mundo humano, pero el del capital, sin espacio para la fraternidad, amistad y compasión.

Palabras clave: Tiempo, Trabajo, Capitalismo, Modernidad

\section{The discontents of the contemporary world: performance and time}

\section{Olgária Matos}

This essay proposes a reflection on the institutional organization of time and labor, according to the demands of contemporary capitalism and the dynamics of modernity. Such demands derive in alienation and domination of men by market. This logic refuses the temporality of experience, resulting in the shrinking of the space for knowledge, for freedom, for happiness; and leaving men to the loss of sense and the loss of the control of its own time and of its own life. This ideal is conducted by the principle of performance, labor production. Such logic is filled with competitiveness and with a sort of culture of hate; which promotes elimination and ferocity, instead of cooperation and solidarity. It also takes hold of important democratic spaces, such as education, that is no longer "education for freedom" but becomes instead "education for adaptation".

Time in the contemporary world and the labor directed to goals, performances are doomed by the order of urgencies, the cult of means instead of ends. In this context, concepts such as tediousness and monotony must be demarked and differentiated. While tediousness configures the time where the past repeats itself continuously into the present, without the loss of the future; monotony is a time that became stagnated, a time that expresses itself in the anxiety to "kill the time", to "make it pass". It is a modern discontent, illness. A pathological time, since its emptiness of meaning has the stress as an ideal. In the monotony, time does not pass. It is alienated in the loss of senseless actions. The contemporary discontent expresses itself in a feeling of monotony or "chronic tediousness", conducting men to the devaluation of all values. In the contemporary political life, "to be is to be noticed": a narcissist, regressive and omnipotent formula of occupying the public space. It is the logic of the spectacle and corresponds to the logic of consumption and of permanent substitution of goods, where nothing fulfills the needs itself created. At last, the contemporary discontent displayed in this pathologic time is circumscribed to a world where the law of value is the only one that counts; not the human world, but the capital world; without space for fraternity, friendship or compassion.

Keywords: time, labor, capitalism, modernity.

\section{Olgária Matos}

Possui graduação em Filosofia pela Universidade de São Paulo, mestrado em Filosofia na Université Paris I (Panthéon-Sorbonne), doutorado em Filosofia pela Universidade de São Paulo (1985) e pós-doutorado na École des Hautes Études en Sciences Sociales (França). É professora aposentada da Faculdade de Filosofia, Letras e Ciências Humanas da Universidade de São Paulo. Atualmente também leciona na Universidade Federal de São Paulo (UNIFESP), sendo a coordenadora do curso de Filosofia. Também é professora no Mestrado em Comunicação e Cultura da Universidade de Sorocaba (Uniso). É autora, entre outros, de As barricadas do desejo, Sombras e Luzes do Iluminismo, Discretas Esperanças: reflexões filosóficas sobre o mundo contemporâneo e Filosofia: a polifonia da rą̃ão. 